\title{
Reflex Irritability Score
}

National Cancer Institute

\section{Source}

National Cancer Institute. Reflex Irritability Score. NCI Thesaurus. Code C81319.

A component of the Apgar score, it is the numerical value assigned to the neonate's

response to stimuli, such as a mild pinch. 0 = no reaction; 1 = grimace; 2 = grimace with $a$ cough, sneeze, or vigorous cry. 